\title{
Sciendo
}

\section{Coronavirus COVID - 19, a complex issue between health, economy, politics, and communication.}

\author{
Alessandro Figus \\ Professor - Link Campus University (Italy) and Vice Rector - International Institute of \\ Management (Moldova) \\ Email:a.figus@unilink.it
}

Doi: $10.2478 /$ gssfj-2020-0001

\begin{abstract}
The author wants to talk about a new reality surrounds us, a new atmosphere, a new condition of life in the post-globalization era at the pandemic time of the coronavirus COVID -19. The pandemic, it is said, started from communist China with a centralized and at the same time globalized economy, but today the centre of all the global problems. This it is intended to be a first analysis where economics, politics and communication intertwine and interact with the health problem which has highlighted the weaknesses of a society which has been too busy for a long time to regulate GDP.
\end{abstract}

Keywords: Coronavirus COVID -19, economy, health, politics, economy.

\section{Introduction}

We are going to celebrate Christian Easter on April 12, 2020, a new reality surrounds us, a new atmosphere, a new condition of life. Are we really in the post-globalization era, are we really at the end of the capitalist system and its hedonistic form, or are we simply at a stage of transformation of society? This is a new pandemic that forces us to ask ourselves these questions, not the first that humanity is forced to face, probably not even the last.

The people infected by the coronavirus COVID-19 in the world today (WHO data, March 2020) are over one million and 300 thousand, the deaths almost 75 thousand. Europe is the most affected continent, with over 50 thousand deaths: $85 \%$ of which in Italy, Spain, France, and Great Britain.

The pandemic, it is said, started from communist China with a centralized and at the same time globalized economy, but today the centre of all the problems, that is Wuhan, removed all the barriers erected on January 23. The isolation has ended. The city from which the coronavirus epidemic spread has reopened roads, the sea, rail, and air links. Europe is the most affected continent, with over 50 thousand deaths: almost $85 \%$ in Italy, Spain, France, and Great Britain. 
The pandemic, it is said, started from communist China with a centralized and at the same time globalized economy, but today the centre of all the problems, that is, Wuhan removed all the barriers erected on January 23. The isolation has ended. The city from which the coronavirus epidemic spread has reopened road, sea, rail and air links. A video released by the Chinese state media shows images of the removal of the barriers from a motorway toll booth and the first cars queuing to leave the capital of Hubei, inland China. Europe, America, even Africa, and Australia are still or barely engaged in the hard battle to stem the spread of the virus.

Although most of the cases were originally concentrated in the Chinese city of Wuhan, the virus left the country and spread to 209 countries, including Italy and Spain. In particular, the virus continues exponentially with its expansion outside of China, with major outbreaks in Europe. For the moment it seems that the state of alarm will last much longer, probably the economic crisis will affect health policies very soon.

The problem is not only sanitary but also economic, at the same time. For Italy that is already in recession, a new catastrophe, which goes hand in hand with serious care and clinical problem. European solutions are being asked for, but Europe has been absent and seems to propose only vexatious solutions. The former Minister of Economy, Pier Carlo Padoan, says that "Eurobond and Mes have become "toxic words", now unmanageable. It would be better to get rid of them and then start discussing again using a new vocabulary" (Padoan, interview on the Foglio, 8 April 2020).

We have to start from here! The coronavirus counts two aspects, the sociosanitary one and its derivatives and the second, the economic crisis; this is already affecting the first factor and in the long run, it will be decisive for the management of everyday life.

But how does the coronavirus affect the economy? At the beginning of March, the OECD warned that the world economy will grow by half compared to forecasts if the coronavirus crisis gets longer and worse. As a worst-case scenario, the global economy is expected to grow by $1.5 \%$ in 2020 , compared to 3.2\% last year (OECD data, March 2020). Central banks have injected more liquidity into the system, with the Fed acting more aggressive. At the beginning of March, the OECD warned that the world economy will grow by half compared to forecasts if the coronavirus crisis gets longer and worse. As a worst-case scenario, the global economy is expected to grow by $1.5 \%$ in 2020, compared to $3.2 \%$ last year (OECD data, March 2020). Central banks have injected more liquidity into the system, with the Fed acting more aggressively. Central banks have injected more liquidity into the system, with the Fed acting more aggressively. With rates negative or close to zero in most 
G9 countries, large-scale asset purchases and financial structures are the main tools available from central bankers. We believe that central banks have been extremely efficient in facilitating liquidity and financing in the investmentgrade universe - so far we see few effects outside investment grade. Global finance is trying to stem the crisis, coming in with funding, liquidity and fiscal stimulus. But China, with its huge economic and liquidity reserves, is still the one with the highest power in the world, willing to throw itself on the market. Already a first operation, which I consider very aggressive and emblematic, was advanced at the beginning of February by the Chinese Central Bank to give "reasonable and sufficient cash to the banks".

We believe that central banks have been extremely efficient in facilitating liquidity and financing in the investment-grade universe - so far, we see a few effects outside investment grade.

Global finance is trying to stem the crisis, coming in with funding, liquidity and fiscal stimulus. But China, with its huge economic and monetary reserves, remains the most powerful in the world and is willing to throw itself on the market. Already a first operation, which I consider very aggressive and emblematic, was advanced at the beginning of February by the Chinese Central Bank to give "reasonable and sufficient liquidity" to the markets after the spreading of the Coronavirus COVID-19. We are talking about a 1.2 trillion yuan intervention (about 154 billion euros) with which the Chinese Central Bank, hence a socialist country, has injected into the financial system liquidity for 400 billion yuan ( 51.68 billion euros) to maintain an adequate level of liquidity during the period of prevention and control of the epidemic.

China has therefore already made a 380 billion yuan operation by refinancing mechanisms at a rate of $2.4 \%$ and another 120 billion yuan at a rate of $2.55 \%$, with 100 billion yuan now maturing, leaving a net inflow of 400 billion yuan (Chinese BC data, February 2020). This situation appears very dangerous and the newspapers of the world do not talk about it widely, being too busy talking about the pandemic crisis; however, the injection of liquidity will lower interest rates on the money and bond market and will help to reduce interest rates on the loan market, at which price it will be seen in the long term.

All of them, especially in Europe, are in a bit of a rush to implement the fiscal stimulus, where there are some challenges as far as small businesses are concerned. The missing piece to complete the puzzle is positive news regarding the COVID-19 treatments, but we hope it will improve in the coming months. Economists do not help in understanding what will happen. We believe that the COVID-19 crisis will persist longer than many investors suspect and that the economic damage will be deeper and potentially more long-lasting. Therefore, I believe that the best approach is to concentrate 
capital on companies with stronger balance sheets and financial profiles and with the ability to maintain capital returns better than their competitors, but on this point, I do not see how public finance can intervene. In other words, it is not very clear what is the support of the states, in our case the European Union, to stem the state of crisis in pandemic times, health crisis, economic crisis, political crisis and which transforms the communication system, not only public but also interpersonal communication, social networks triumph and do business.

Some management analysts (Lazard Frères, March 2020) predict that the economic impact will be extremely violent as it combines a shock of demand and a shock of supply. However, it seems positive that this will happen in a global economy that is accelerating and therefore more resilient to the shock than, for instance, a year ago. Considering the magnitude of the shock and its time dimension - as a priority - the key lies in the measures taken by governments to support activity and, above all, the viability of economic actors.

Unlike the 2009 crisis, governments are currently very reactive, seeking to put in place implementing measures even before the negative impact on the economy begins. The challenge facing governments is to support businesses and households during the crisis, ensuring that the economy recovers as quickly and as strongly as possible.

In reality, the problem for everyone is that central banks must guarantee the liquidity of the financial markets and ensure that financial flows to companies are not exhausted, thus guaranteeing the liquidity of banks. For governments, the first step will be to compensate for the loss of income of households and businesses, as well as guaranteeing loans to businesses. In the very short term, the priority is to avoid bankruptcies by extending the terms or the linking of loans. The ability to do so, for all companies concerned, in the very short term remains uncertain. China has liquidity, other countries do not.

Nobody is surprised at this point, but the macro data that will be known from now on already include the strong impact of COVID-19, which we remember started to affect Europe as early as February, but it was only in March that the economic activity-induced coma deepened. SMEs in March were released this week, and they are the first relevant main indicator after the spread of COVID-19 in Europe. The SME services index in Europe stands out above all, falling to the lowest standard (from 52.6 in February to 28.4, compared to the previous low of 39.2 in February 2009, OECD 2020 figure). This decline would be in line with the opinion of the Chinese SME in February, later in the spread and containment of the virus. Meanwhile, in the United States, weekly unemployment claims have risen to 3.2 million. Historical maximum 
in line with the speed of this crisis. US GDP could drop 30\% in the second quarter of the year and unemployment has already risen to $12-13 \%$ due to the coronavirus pandemic (Janet Yellen, former Federal Reserve Governor, U.S. Central Bank, CNBC, March 2020). According to Yellen, "the economy is amid a shocking decline that is still not reflected in the data.

The market is prepared for this type of data, which will not generate optimism but should not be a catalyst for further falls. The problem especially for countries such as Italy, where the crisis already existed due to the near-zero growth, is the extent to which the containment measures will be successful and how much the monetary and fiscal measures adopted will help to regain growth.

The coronavirus (COVID-19) has put the world on the edge from both a health and social point of view, but it is the economic crisis that is worrying in the long term. For the coronavirus a vaccine will probably arrive soon, but who will produce the vaccine to the new globalized crisis for the economy? All these concerns are highlighted by international capital markets that have oscillated between hope and fear in recent weeks. Certainly, there is hope that the pandemic will be contained and the fear that the growing global spread of the new coronavirus will cause a significant slowdown in world economic growth. We will perhaps only know the truth in the coming months. We will certainly have positive responses in the medical sector.

Bill Gates is talking about it as well, and he is also pointing the finger at environmental issues and their derivatives. In fact, for a long time Gates has been explaining why he cares so deeply about climate change and what makes him optimistic that the world can avoid the direst effects of the climate crisis. (Bill Gates, Kindle, 2020). The only one who had foreseen everything seems to be the only one with clear ideas. Microsoft's founder Bill Gates, in 2015 (Bill Gates, youtube, 2015) had predicted the threat of a phenomenon like the one going on during a Ted talk, and now he left his company's board of directors to devote himself full-time to the philanthropic activities of his foundation, which donated $\$ 100$ million to help fight the coronavirus COVID-19. Bill Gates says that "the blockade of all activities in coronavirusaffected countries could last for a few weeks, but if executed well it could stop the pandemic and allow activities to restart fairly quickly" (Bill Gates, La Stampa, March 2020).

Although various possibilities have been studied to advance research on a new drug using artificial intelligence, Bill Gates is confident that a vaccine will arrive soon, but that the tension must remain high because the pandemic problem is a concern that countries will have to take into account in the near future. Today, while waiting for the vaccine, the first indications are that 
existing drugs can reduce the duration of the disease. Elsewhere, it seems that daily life is beginning to return to normal. Chinese consumers are getting back into action and the country's production is slowly recovering. Also, the return to normality in Wuhan seems to be getting closer and closer. The health issue is becoming an issue for the economy as well; this is how Bill Gates deals with it, so perhaps the states will have to deal with it in the same way.

Especially in Europe, the fact that the pandemic has reached the indicators of the economy is mainly reflected in recent leading indicators and the indexes of purchasing managers in the eurozone. In the United States as well there are clear signs of a turnaround in the labour market with the disruption of global value chains and the increasing limitation of social life that are putting the entire American economic model under enormous pressure. The impact on the economy is serious, so in the years to come economists and analysts will have to adjust their estimates of economic activity and profit forecasts, making them more compatible with the new challenges highlighted by the pandemic crisis. In light of these economic events, the likelihood of a recession in the world economy is also evident, an unexpected new scenario.

In the short term, we are looking at short-term actions, defensive actions such as the one taken by the US Federal Reserve, which has promised to buy unlimited US government bonds and mortgage-backed securities, which would revive monetary easing. The Coronavirus, reported the Federal Reserve note, "is causing enormous difficulties in the United States and the world", it is now clear "that our economy will face serious turmoil" (money.it, March 2020).

For the Fed, "aggressive efforts must be made, both in the public and private sectors, to limit job and income losses and promote a rapid recovery once the disruptions have subsided.

Against this background, the Federal Reserve has indicated that it will "buy government bonds and MBAs (Mortgage-backed securities) for the amounts necessary to support the smooth functioning of the market and the effective transmission of monetary policy" (money.it, March 2020).

Faced with the contingencies caused by supply and demand, it is important to ensure the functioning of the markets and improve the flexibility of financing conditions in the financial markets. Monetary and fiscal policies are becoming two sides of the same coin, as many governments are applying monetary and fiscal stimulus measures in series. The European Union does not seem to be tackling this issue in time and cannot stop the uncertainty that is causing serious unrest in many European economies, first of all in Italy. Even if the end of the market collapse does not yet seem to be in sight, there are still no concrete countermeasures to be seen, and in any case, it is not as if China is 
in good shape: indeed the worst figures in the last 50 years are emerging. On the other hand, financial markets have fallen by almost $40 \%$ in the European case, which historically places this crisis in one of the worst afflictions ever. It remains to be seen whether the current situation is damaging the capacities of companies. Much has to do with the duration of the pandemic and the irreparable damage it will do to the economy. The response of governments will play an important role in limiting the effects on the economy. Take the air transport sector, for example. For the aviation sector, estimated revenue losses are around USD 30 billion (figures from the International Air Transport Association, ATS, March 2020). According to ATS, virtually all losses are expected to affect airlines in the Asia-Pacific region, which are facing a 13\% drop in passenger demand during the year. Some companies have reported the effects of the epidemic on their business. Air France-KLM and Qantas groups in Australia felt a potential financial blow. Qantas claimed that the coronavirus could reduce profits for the fiscal year ending June 30 to $\$ 66$ million, with losses of around $\$ 30$ million. Air France-KLM estimated a profit reduction of $\$ 216$ million between February and April this year (money.it, March 2020).

The all-Italian case of the airline company Alitalia is worth to be mentioned. In the "Cura Italia" decree, the Italian government gave a positive response concerning the rescue of the former Italian flight company. Due to the ongoing coronavirus emergency, it is in fact impossible to find buyers; this is because Alitalia, as the other previously cited companies and as the whole system of world air transport, is in deep crisis. In 2020, the sector could record a turnover decrease of between 63 and 113 billion dollars, a fifth of the entire world turnover. Saving the airline industry will cost up to $\$ 200$ billion (IATA data, 2020). In reality this crisis it is not so different than in the past (Arguin, Navin, Steele, Weld, Kozarsky. SARS travel alerts and advice. Emerging Infectious Diseases, 2004) we have a lot of elements to think it is very similar to pandemic situation of the past years as well the SARS in 2002-2004. The big difference is the global reaction and the consciousness by everyone, thanks also to widespread communication.

The last interesting aspect is that COVID-19 has manifested itself in an increasingly worrying way in some of the most polluted areas in the world, a reason that could justify the high number of infected in the Italian Region of Lombardy, one of the most industrialized areas in Europe, in which critical environmental conditions have been a prominent issue for a long time. The question to be asked is: why did the COVID-19 exploded so virulently in those areas? In Lombardy the concentration levels of particulates (Pm10) are among the highest in Europe and in the world, and this situation has persisted 
for many, too many years. It is certain that high levels of Pm10 also cause problems for the respiratory system which would therefore be more sensitive to the complications caused by this new virus. The longer we are exposed to this highly polluted environment, the more likely our respiratory systems are to become weaker and, therefore, more fragile in fighting against the effects of coronavirus COVID-19. It is no coincidence that a recent study by the Italian Society of Environmental Medicine (Sima, March 2020) highlights a relationship between the excess of the legal limits of concentrations of PM10 recorded in the period 10-29 February and the 66 cases of infections, showing one undeniable thing: changing our lifestyle, sustainable production and consumption resulting a reduction in pollution is certainly good. Especially regarding the air we breathe and what we eat: it is known that our immune system would certainly be strengthened where the use of certified organic foods is preferred.

An optimistic remark: once the virus is controlled, perhaps the air transport sector will start again, but only with those who have managed to resist. We will be placed in a scenario with unprecedented fiscal and monetary stimuli that would lead to a significant market appreciation and this could also happen in other sectors, therefore, the action of central banks becomes fundamental. Central banks must implement a stimulus plan both in the United States and in Europe where there is no understanding of what the EU action such as the role of member states, often in conflict with each other, problems due to the lack of joint European action; the EU appears to be more and more a club (Figus, Sistema Europa, Eurilink, 2019). COVID 19 lays bare the misunderstandings and divisions of the new European Union of 27, and where EU solidarity is faced with the test of nine, will the expectation for the Eurogroups from now on be an opportunity to unite or to divide? The United States, for example, has launched its largest stimulus package and is already planning to continue with another. The mere determination of monetary and fiscal organizations to tackle an unprecedented crisis has undoubtedly improved. The pandemic has a cost, while its value remains uncertain.

We still do not know exactly how much this pandemic will cost and investors are now focused on knowing when it might peak and when the vaccine will be available when everything will return closer to normal. There are some encouraging signs in Europe, but we must be cautious. However, a more accurate scenario is taking shape. The stimulus plans of governments are providing great support, but they will probably not compensate for any prolonged closure period. For example, Italian measures could compensate for a few weeks of recession, but then what? The problem is that the blockade cannot last long. As in China, there will only be a gradual return to normality 
in the post-confinement period. And the process could take time. The economy will certainly recover, but the improvement could be slowed down by the extension of social distancing measures. Moreover, it is not known how quickly the borders will reopen and there is no way of knowing if the virus will return in the autumn. The Schengen agreement has also failed, as has the Erasmus program, which was the flag of Europe.

The coronavirus problem is a health problem that triggers chain reactions involving both economics and politics, the entire society in general in any place, it is a global issue that puts people's social security at risk.

The coronavirus epidemic has a very important social impact because it forces us to change a series of behaviours that are quite fixed in our lives. It involves changing habits, changing patterns of relationships, everything that sustains our lives that is routine. It also generates fear and danger, triggers a very strong reaction of uncertainty that leads us to sometimes adopt more automatic reactions which are not the best behaviours to be taken.

It is a very new situation for most of our population, who have never experienced circumstances of this kind that directly affect our daily behaviours. Added to this, this situation has an impact on our daily life that requires us to adopt certain behaviours. In addition to a medical problem, the coronavirus epidemic is a problem of social behaviour. Containing and mitigating the spread of the virus leads to changes in behaviour and often governments set the rules. Citizens must abide by the rules set by doctors and politicians (www.governo.it/it/coronavirus-dieci-regole). We act in the name of national security, the answer is primarily the health care system, ie it comes from a specific medical approach, but there is a previous line that we must maintain that is to change our behaviour. People usually have difficulty in changing behaviours, we find ourselves in a very special scenario where our usual behaviours are disarmed and we must quickly introduce new behaviours to stop the virus.

On the one hand, the new behaviours are those that fall within the recommendations of reliable health authorities. We must make a very important effort to adhere to the recommendations and rules.Today's recommendations are social distancing, i.e. avoiding all situations and all places that promote close contact with other people. To avoid possible contagion, we need to take precautionary measures for contact with the virus, washing hands, cleaning surfaces and all this involves adopting new habits (www.governo.it/it/coronavirus-dieci-regole).

New routines need to be created; we need some behavioural cues to do this. For example, hand washing, we need to start training to do hand washing in certain repetitive cases, when we enter and leave other places, at certain times 
of the day by default, we should establish hand washing as a behaviour in principle, forced to be automatic in the coming months. What it means from a psychological point of view today is a great effort to establish new habits and should be specifically focused on the recommendations of health authorities.

The effort also lies in not doing the other things we do when we are insecure, restless or desperate, and our minds generate behaviours to calm us, such as buying things like toilet paper, which is not important. Containing and mitigating the spread of the virus leads to changes in behaviour and often governments set the rules. Citizens must abide by the rules set by doctors and politicians (www.governo.it/it/coronavirus-dieci-regole). We act in the name of national security, the answer is primarily the health care system, ie it comes from a specific medical approach, but there is a previous line that we must maintain that is to change our behaviour. People usually have difficulty in changing behaviours, we find ourselves in a very special scenario where our usual behaviours are disarmed and we must quickly introduce new behaviours to stop the virus.

On the one hand, the new behaviours are those that fall within the recommendations of reliable health authorities. We must make a very important effort to adhere to the recommendations and rules. Today's recommendations are social distancing, i.e. avoiding all situations and all places that promote close contact with other people. To avoid possible contagion, we need to take precautionary measures for contact with the virus, washing hands, cleaning surfaces and all this involves adopting new habits (www.governo.it/it/coronavirus-dieci-regole).

New routines need to be created; we need some behavioural cues to do this. For example, hand washing, we need to start training to do hand washing in certain repetitive cases, when we enter and leave other places, at certain times of the day by default, we should establish hand washing as a behaviour in principle, forced to be automatic in the coming months. What it means from a psychological point of view today is a great effort to establish new habits and should be specifically focused on the recommendations of health authorities.

The effort also lies in not doing the other things we think we do, when we are insecure, restless or desperate, and our minds generate behaviours to calm us, such as buying things like toilet paper, is not important. We should not clutter ourselves with products, today we should put all our attention to repeat again and again the behaviours that are recommended by health authorities so that they are assimilated by our brain. If we do not, it is very difficult for them to 
become habits, and if they do not become habits, they tend to decline because the most important answer today is social, not individual behaviour.

It is clear that both in economics and politics, and for society as a whole, this is an exceptional situation that affects people's lives not only from a health point of view but also psychologically. Global behaviours are homologated, so frequently we adopt recommended behaviours that show us that, together with other measures in some countries, this is how it works today. Indeed, countries that have adopted strong social distancing and measures of this kind, such as Korea, despite being rapidly exposed to the virus, have managed to keep the disease under control. From a behavioural point of view, we can help by adopting certain behaviours to mitigate the impact that the virus has on our society.

Even psychology and security have changed after the coronavirus, without realizing that behaviours become global and shared. All this stems from the unforeseen, the unpredictable, the uncertainty about demographic and temporal ranges, the lack of certainty in information around the world and the potential deadly effects of a new virus that has already reached the state of a pandemic, has triggered fears and, at times, panic and psychosis in world society. Even the trade war between China and the United States seems to have stopped, due to a virus allegedly originating from ancestral and unhealthy habits - the eating habits of an Asian market, which even shifted the natural interest aroused by the presidential elections in the United States.

There is no doubt that among the elements that characterize the crises are surprise, uniqueness (each crisis is unique), urgency, destabilization and a downward trend in the quality of information. these days just read the newspapers or watch television or visit, social networks: all shared, all homologated, even the falsehoods that we now call "fake news" and that often through communication put society in danger. The fake communication is a danger, there is no regulation, no valid security system even if some systems try a self-regulation, for example Facebook $76 \%$, Twitter only $41 \%$ (the daily fact, April 2020). Communication in times of crisis is very important.

Crisis communication management seeks to limit risk and exercise the greatest possible control over its implications, and has within its fundamental objectives the transmission to society of peace of mind, control of the situation and confidence in the future. It is essential to always try to act proactively when informing citizens, paying particular attention to those affected, responding to the media and controlling the dynamics of the events that may occur. In order to manage a crisis effectively, it is necessary to establish solid channels of communication with the different sectors of 
society, as well as identifying which of them are most affected by the situation in order to establish a prioritised communication.

Even with the coronavirus, the reaction time and honesty of governments will be essential factors for a favourable resolution. Inevitably, time affects the messages and content being communicated, so it will always be necessary to assess at what stage of the crisis we are and which are the requests for more information that exist at that time, not only towards citizens but also in relation to society.

In conclusion, are we sure that every day that passes means one day less crisis? There is too much uncertainty. It is true that the actions of the central bank offer substantial protection, but everything can only be defined over time.

Time becomes an essential factor. The COVID -19 pandemic is changing and will change the methods and techniques of communication even more in the future. Both those of individuals and those in the external approach of companies and organizations in general. It is easy to see a change in the style and content of communication between economic and non-economic institutions.

To tell the truth, many advertising campaigns, designed before the outbreak of the pandemic, are still ongoing and are focused exclusively on promoting the quality of the product or service offered. Seen on television, they seem to be the remains of a long-gone era and, according to some analyses of viewer satisfaction, they even arouse a sense of irritation or antipathy in certain sections of the population. With negative effects. But the most recent and upto-date messages and communications are increasingly aimed at underlining, the social commitment of companies and organizations. This is what citizens expect. New attitudes and new approaches are emerging from people, especially in more developed countries that, according to Renato Mannheimer (Facebook, 2020), are not limited to the mere production and sale of products and services, but that also considers commitment and social responsibility. Towards workers, towards the environment, towards the country.

In short, the coronavirus is changing the world, either the world needed new models and takes advantage of the crisis. With the outbreak of the COVID 19 emergency, citizens change their needs and their sensitivity to, for example, the environment or social issues. Companies understand this interest and are preparing to meet these demands. Companies and organizations are now being asked to make an active contribution to the fight against the pandemic, and companies are happy to make donations, considering social commitment as one of their objectives, and economic cost to be evaluated also in terms of return on investment; indeed, an investment that will also bring benefits in 
terms of sales. Covid-19 will also change corporate communication, communication also changes from this point of view, largely transforming the communication of many institutions, economic and not, depending on changes in the expectations of citizens, a real and continuous evolution of public opinion is taking place and not only economy but also politics will be overwhelmed by all this.

\section{References}

Gates B., How to Avoid a Climate Disaster: The Solutions We Have and the Breakthroughs We Need, Kindle Edition, 2020

Figus A., Sistema Europa. L'organizzazione politica dell'Unione europea, il complesso cammino verso l'unione politica. Eurilink University Press, Rome, 2019.

\section{Web references}

www.money.it

www.lastampa.it

http://www.lazardfreresgestion.fr

www.oecd.com

www.who.int

www.salute.gov.it

https://ec.europa.eu/health/home

http://www.cdc.gov/ncidod/EID/vol10no2/03-0812.htm.

http://www.governo.it/it/coronavirus-dieci-regole

https://www.ilfattoquotidiano.it/2020/04/09/coronavirus-e-fake-news-facebook-ne-

blocca-il-76-twitter-solo-il-41/5765761/

http://www.simaonlus.it/wpsima/wp-content/uploads/2020/03/COVID19_Position-

Paper_Relazione-circa-l'effetto-dell'inquinamento-da-particolato-atmosferico-e-la-

diffusione-di-virus-nella-popolazione.pdf 